refugees did. However, the price of this early start to employment was an early stop to language training. The mean duration of the language training of privately sponsored refugees was 2.7 weeks less than for government-assisted refugees.

\section{Language Training}

Government-assisted refugees received living allowances while attending language classes, but privately sponsored refugees did not; they were generally supported by their sponsors. The tradeoff between early employment and immediate language training was one of the most contentious issues within sponsorship groups and also among government settlement officers. The study found that, overall, government officials tended to give priority to language training, whereas sponsors tended to give priority to employment. Many sponsors interviewed mentioned that the refugees themselves gave priority to employment and economic independence.

Furthermore, although language training itself was paid for by the government for both government-assisted and privately sponsored refugees, the study encountered allegations that government-assisted refugees were given priority for seats in language classes, on top of the fact that there was as much as a three to four month wait for seats.

\section{Other Differences}

Privately sponsored refugees had the assistance of their sponsors in finding jobs. Government-assisted refugees had government support while they studied English or French. These conclusions point to a larger problem of inequitable treatment of refugees. Levels of material support given to privately sponsored refugees varied according to sponsors; those given to government-assisted refugees varied according to local CEC's interpretations of guidelines. Moreover, some CEC officers noted that privately sponsored refugees sometimes expressed resentment at receiving less than government-assisted refugees; for instance they were often given hand-me-down clothes instead of money for new items. Some refugees were troubled by feeling indebted to a private benefactor, some CEC officers noted, and preferred receiving monies on the basis of government entitlement.

Refugees' material dependence on sponsors may pose problems for the emotional relationship between refugees and sponsors, one of the studies (based on in depth interviews with sponsors) suggested. On the sponsors' part, it may reinforce a paternalistic and possessive attitude. On the refugees' part, it may induce dependency, suspicion, or even dishonesty. If all refugees were entitled to certain basic funds from the government, the study suggests, these emotional dangers might be less significant; and the problem of inequity would be ameliorated.

Cost

The average cost of settling a privately sponsored refugee was $\$ 753$ less than for a government-assisted refugee, the study found. Private sponsors spent an average of $\$ 1,347$ per refugee. The government spent an average of $\$ 2,100$ on basic living allowances and language training allowances for each government-assisted refugee.

The study suggests that the apparent savings of $\$ 753$ is somewhat misleading since the questionnaire on which the statistic is based asked sponsors not to include material contributions such as donations of clothing and furniture in their summaries of their expenditures. However, it is even more misleading for the report to discount these savings in this way. Donations of used items do no represent expenditures in the same way cash disbursements do, and the distinction is extremely important to finding ways to make refugee settlement cheaper.

\section{Willingness to Sponsor Again}

The majority of sponsors of Indochinese refugees would sponsor again if they felt there were a need and if they felt sure that there would be sufficient money and help to see the sponsorship through, the study found.

Fifty-nine per cent of sponsors surveyed indicated that they would be prepared to sponsor again; $\mathbf{2 8 \%}$ indicated they might be; and $13 \%$ indicated they would not. Some of these sponsors cited specific conditions that would have to be met for them to be willing to sponsor again. Their most important concern involved need, with sponsors saying such things as,

"I would sponsor again if a real 'need' can be demonstrated. I am not totally convinced that all the Indochinese were 'refugees' in the true sense"; and "I would sponsor again if I were satisfied that, given world conditions, it is those refugees who are most in need of our help who are being admitted to Canada."

Their second most important concerns involved means: sponsors wanted to be sure that there would be more government and agency support services available; that there would be an equitable sharing of workload; and that there would be adequate funds for the sponsorship.

In this connection it is interesting to note that a willingness to sponsor again was more likely to be expressed by sponsors associated with a church as a parent organization. Some churches and other national organizations had signed umbrella agreements with the federal government to facilitate sponsorship by their constituent groups. These umbrella agreements simplified the bureaucratic procedures of sponsorship and assured sponsors of back-up assistance in case of an emergency. These assurances had often made the difference between choosing whether or not to sponsor the first time around.

Finally, government leadership was thought to be critical in motivating sponsors. Church leaders felt this was so, and sponsors and agencies attributed the present decline in sponsorship, not to a decline in public interest or willingness to sponsor, but to a lack of continuing government interest and leadership.

\title{
Miscounting Refugees a Case Study of Lebanon
}

by Howard Adelman

"Refugee" is an equivocal term. It is used in many different senses. It describes people whose homes are destroyed by earthquakes; people who are driven from their homes during wars; people who flee persecution in their countries and become "Convention refugees". By failing to distinguish the various different senses of "refugee", gross differences in numbers of refugees can be reported.
Given the complexity of the situation in Lebanon in particular and in the Middle East in general, it is not surprising that such differences characterized the reCont. on page 6 
Cont. from page 5

ports on the number of refugees following the recent invasion of Lebanon by Israel.

Israel Gravinsky, head of the Lebanese Relief Section within the Finance Ministry of Israeli government, was reported to have estimated that there were 20,000 "roofless" people in Israeli-occupied southern Lebanon in July of 1982 . The caption under a picture of a devastated Palestinian refugee camp south of Beirut published in an August issue of Newsview also reported that 20,000 people were left homeless by the Israeli invasion. On the other hand, a full-page advertisement in the New York Times, sponsored by the Ad Hoc Committee in Defense of the Palestinian and Lebanese People, protested vehemently against the invasion which produced 700,000 refugees. An advertisement in the August New York Review of Books, sponsored by the American Friends Service Committee, solicited donations to help the 600,000 refugees resulting from the recent attack on the Palestinians and Lebanese.

How many refugees were there in Lebanon following the invasion? 20,000 or 700,000 ? To answer the question in a useful and accurate way that can contribute to planning relief, you have to categorize the refugees according to their situations and clarify terminology accordingly.

First you must distinguish Lebanese nationals, who would technically be described as internally displaced persons, from Palestinians in Lebanon. The Lebanese in turn have to be divided into five groups:

(1) those in southern Lebanon whose homes were destroyed or so damaged as to be uninhabitable as a result of the Israeli invasion. In August 1982, there were approximately 250 homes destroyed in Tyre and four times that many in Sidon, resulting in about 6,250 Lebanese refugees or "roofless nationals" in southern Lebanon.

(2) those who, as a result of the Israeli defeat of the Palestinians in southern Lebanon, returned to homes destroyed or so damaged as to be uninhabitable as a result of the civil war and, in particular, the Palestine Liberation Organization (PLO) conflict with Lebanese in 1975-76 and after. Six hundred Lebanese Christians have returned to the town of Damour, which was occupied and totally destroyed by the PLO in the 1975-76 war. Of the 6,000 people who once lived there, some have found new homes, but many have been in temporary shelters and may wish to return.
These estimated 5,000 Lebanese refugees are also "roofless nationals", but their situation predated the Israeli invasion; even though some are still "roofless", they can be said to have benefited from the war because they have at least regained their land on which they can rebuild their homes.

(3) those who were refugees as a result of the 1975-76 war but who recovered their homes and their lands following the invasion. 50,000 Lebanese refugees from Nabitieh returned to that city following the ouster of the PLO by the Israelis.

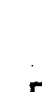


(4) those who have fled Beirut and are temporarily without shelter. $30,000-60,000$ citizens of West Beirut have fled the city, some of whom have lost their homes, but the majority of whom have simply fled the battle scene and are temporarily homeless. These people would technically be described as temporarily displaced persons.

(5) those whose homes are destroyed or so damaged as to be uninhabitable as a result of the Israeli PLO fighting in West Beirut.

(6) those whose homes were destroyed in the internecine fighting in

\section{?ring}

igee

'els

Letter
West Beirut. The numbers of such Lebanese citizens are estimated in the thousands.

Thus, it is accurate but terribly misleading to say that there were over 100,000 Lebanese refugees following the Israeli invasion of Lebanon. There may have been 100,000 Lebanese citizens uprooted in the turmoil in Lebanon in the past few years, but the situations of these people, the causes of their situations and their present needs, differ radically.

If reports on the Lebanese refugees are confusing, those on the Palestinians are even more so. Some Palestinians are registered refugees: basically those who arrived in 1948 following the creation of the State of Israel, and their children. These refugees are entitled to rations and benefits from the United Nations Relief and Works Agency for Palestine Refugees in the Near East (UNRWA). Some are unregistered: basically those who arrived in 1970 following King Hussein's slaughter of the PLO in Black September. Other Palestinian refugees have become Lebanese citizens but have never been struck from the official rolls of UNRWA.

loyd Axworthy nployment gration

year would be privately sponsored, with the exception of any urgent cases for which sponsors were not forthcoming. Based on the number of sponsorship applications made, projections would be made for the second half of the year to indicate the amount of the refugee resettlement budget that would be needed for the sponsorships involving private groups. Any remaining funds would be spent on direct government sponsorship of refugees. In this way, the total intake would be a direct reflection of the efforts of the private sector.

2. All private sponsorship groups would receive a basic allowance of $\$ 500.00$ from the government for each refugee sponsored within the levels tabled in Parliament.

3. The allowance would be increased by $\$ 500.00$ if the refugee sponsored did not have a minimum proficiency in English or French.

4. The allowance would be increased by $\$ 500.00$ if the sponsorship group did not share with the refugee some kinship such as family, ethnic or religious identification.

5. A further $\$ 500.00$ per refugee would be available in a back-up fund to be disbursed to sponsors upon proof of necessary expenditures beyond the basic allowances.
6. Private sponsors would provide the government with audited statements of their expenditures, indicating that any funds left over from the allowances had been donated to an approved charity involved in assisting refugees (e.g., a church or a refugee aid organization).

This model undoubtedly has some shortcomings, and it is only one of many possibilities. But we do not have to solve the problem of a specific model at this time. Legislation requires only that the levels for refugee intake be tabled in Parliament. The same levels as last year could be tabled with the clear understanding that the resettlement efforts will have to be undertaken within greater financial constraints; and that therefore, in order to meet the levels, the involvement of the private sector will be needed. The private sector can then be invited to work out an effective plan for meeting the levels within the government's financial constraints - a plan which at the same time can be fairer to sponsors and more effective for refugees.

Yours Sincerely,

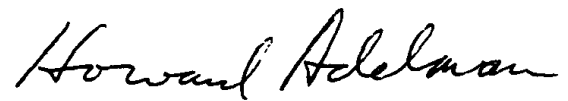

Furthermore, the basic information on camp populations before the invasion is confusing. For example, the official population of the camp that was totally razed, Ein Hilweh, was 24,340 refugees. However, an UNWRA official said that since 1969 the PLO had not allowed them to check their figures. Deaths were often not reported and to compensate for this, UNRWA had adopted a policy of not registering more than five children in a family unless a death was also registered. Some registered Palestinians had moved into town or were working abroad in Bahrain or Kuwait or Abu Dhabi and had leased their camp homes to Egyptian or Syrian migrant workers. Also, PLO volunteers from Pakistan and Bangladesh lived in the camp. In addition, it is estimated that as many as 10,000 unregistered refugees lived in the camp, including many militants and their families. The destruction of Ein Hilweh alone can be estimated to have produced as many as 30,000 "roofless refugees", most of whom would be stateless Palestinians.

According to UNRWA there are approximately 107,000 registered refugees living in southern Lebanon, of whom around 60,000 lived in camps and 47,000 in towns and cities. Some refugee camps were only slightly damaged in the fighting and Palestinians, both registered and unregistered, remained in those camps. On the other hand, Ein Hilweh in Sidon and Rashidieh in Tyre were completely destroyed in the battle between the Israelis and the PLO. El-Buss and Burj el- 


\section{Cont from page 7}

Shemalia were severely damaged. Overall, of these 60,000 registered refugees in camps in the south, and possibly another 25,000 unregistered refugees in camps there, the most reliable estimates indicate that as many as one-half or 42,000 may have lost their homes. In addition, it is estimated that there were approximately 80,000 Palestinian refugees living in the West Beirut and Mount Lebanon area of whom around 18,000 lived in camps. As of this writing, the extent of destruction of these camps is not known but it is probably very extreme. Even if we assume that all refugees living in camps in this area lost their homes in the bombardment, then the total number of homeless Palestinian refugees in all of Lebanon in August 1982 would have been a maximum of 60,000 .

$* * *$
In its report on the situation in Lebanon following the Israeli invasion, the United Nations indicated that 300,000 Lebanese needed aid, a figure that included Lebanese in all of Lebanon who had suffered losses of schools, pock-marked homes, psychological trauma, etc. In its news release announcing aid to Lebanon, the Canadian National Development Agency notes that "UNRWA, which has responsibility for the more than 200,000 registered Palestinian refugees in Lebanon, estimates that the vast majority of them have been displaced, with refugee camps being razed." In addition there are an estimated 100,000 unregistered Palestinian refugees in Lebanon. Thus, if you do not distinguish among the various meanings of the word "refugee" - if you do not distinguish among "stateless" and "homeless" and "in need" - then you can say that there are 600,000 refugees in Lebanon following the Israeli invasion,

\section{Palestinian Refugee Camps in Lebanon, 1980}

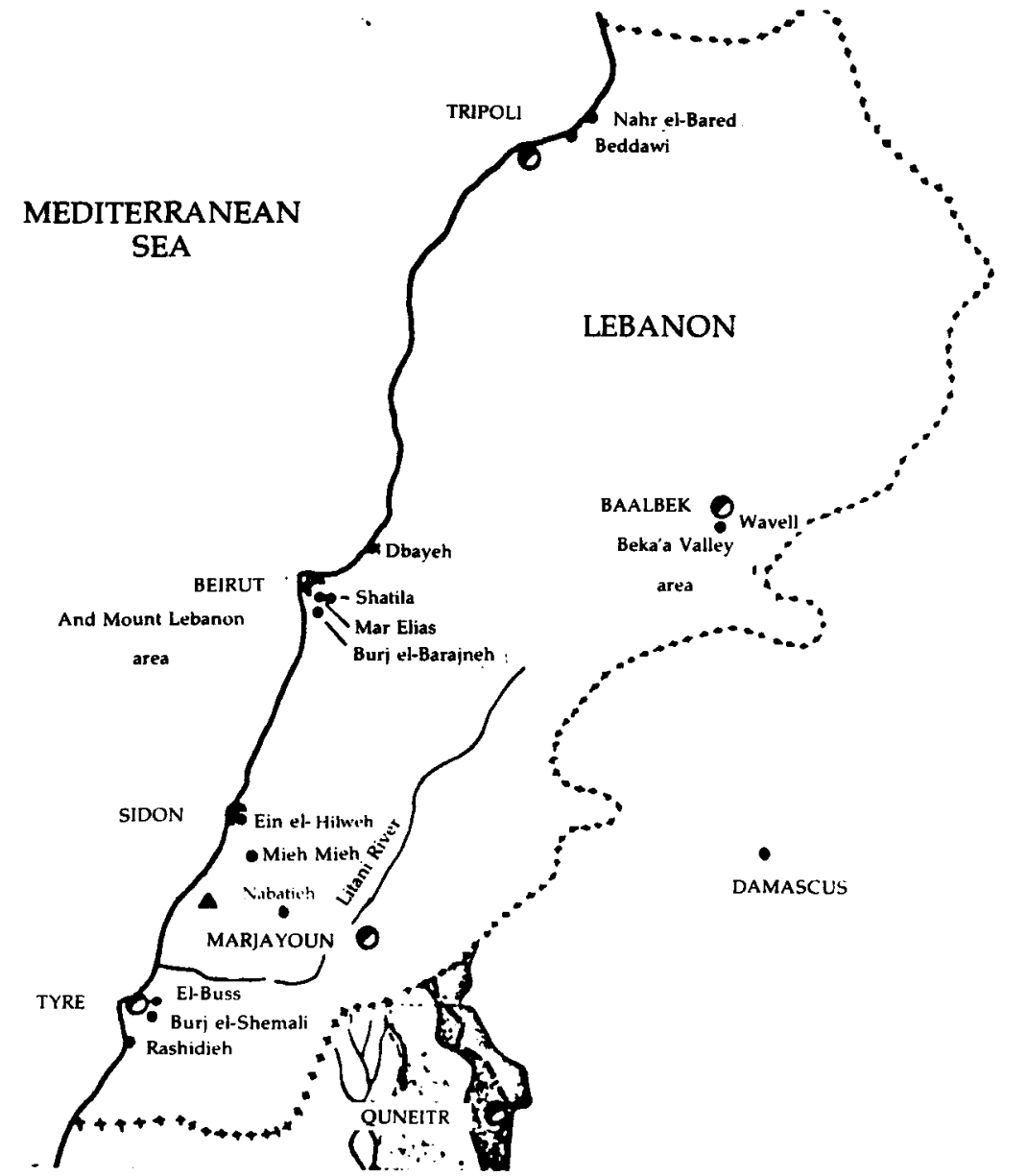

Source: UNRWA (though not strictly as a result of Israeli invasion).

But if you wish to specify what aid is required, and therefore wish, for example, to say how many Lebanese and Palestinians are homeless as a result of the Israeli invasion of Lebanon, then an accurate figure will be 10,000 Lebanese and 50,000-60,000 Palestinians. Probably another 30,000 people in southern Lebanon have had to temporarily flee their homes in order to avoid the fighting. At the same time, 60,000 will have recovered their homes and another 6,000 will have recovered their land. Policy and rehabilitation efforts should be decided on the basis of as accurate a set of facts as possible.

"The introduction of an effective census mechanism to work independently of relief agencies in order to determine in an impartial and professional way the numbers of border-crossers requiring assistance in mass influx situations," is one of nine recommendations made by Sadruddin Aga Khan in his report Human Rights and Massive Exoduses, which will be summarized in the next issue of Refuge.

Howard Adelman visited Lebanon in August 1982 and published a report entitled Homeless Refugees and Displaced Persons in Southern Lebanon, Resulting from the Israeli Invasion of Lebanon, June 1982. The report may be obtained by sending $\$ 2.50$ for the report alone, $\$ 5.00$ for the report with selected appendices, or $\$ 20.00$ for the report with full appendices to: Refugee Documentation Project, York University, 4700 Keele Street, Downsview, Ontario M3J $2 R 6$.

\section{CANADIAN FINANCIAL AID TO LEBANON}

Canada has contributed $\$ 2.55$ million for humanitarian relief in Lebanon since the Israeli invasion of Lebanon in June 1982. A grant of $\$ 950,000$ has been allocated to the United Nations Relief and Works Agency for Palestine Refugees in the Near East (UNRWA), which is responsible for registered Palestinian refugees in Lebanon. The funds are to be used to provide food, shelter and clothing. Another $\$ 450,000$ has been granted to the United Nations Children's Fund (UNICEF), for assistance to homeless mothers and children, mainly in southern Lebanon and the Beirut area. One million dollars has been granted to the International Committee of the Red Cross for relief to displaced Lebanese civilians. Finally, $\$ 150,000$ has been granted to the World Council of Churches for humanitarian assistance to people in southern Lebanon, Beirut, and the Beka'a Valley. 